\title{
Pars plana vitrectomy for the treatment of rhegmatogenous retinal detachment uncomplicated by advanced proliferative vitreoretinopathy
}

\author{
D S Gartry, A H Chignell, W A Franks, D Wong
}

\section{Department of Ophthalmology St Thomas's Hospital, London \\ D S Gartry \\ A H Chignell \\ W A Franks \\ St Paul's Eye Hospital, Liverpool \\ D Wong \\ Correspondence to: M A H Chignell, St Thomas's Hospital, Lambeth Palace Road, London SE1 7EH. \\ Accepted for publication 27 October 1992}

Abstract

A consecutive series of 114 eyes (112 patients) undergoing pars plana vitrectomy for rhegmatogenous retinal detachment not complicated by severe proliferative vitreoretinopathy is presented (follow up 1 to 4 years; mean 19 months). The indications for vitrectomy fell into two main groups: (1) where the retinal view was poor and vitrectomy was required to clear media opacities to allow identification of retinal breaks $(n=62)$; and (2) where technically difficult breaks existed and vitrectomy with internal tamponade was used to relieve vitreoretinal traction and facilitate retinal break closure $(n=44)$. In some of these cases the need for scleral buckling was eliminated. A smaller third group $(n=8)$ existed where the position of the break(s) was uncertain in the presence of an adequate view. The success rate with one procedure was $74 \%$ and with further surgery retinal reattachment was achieved in $92 \%$. At 6 months after further surgery, beyond which interval no new failures were encountered, best corrected visual acuity

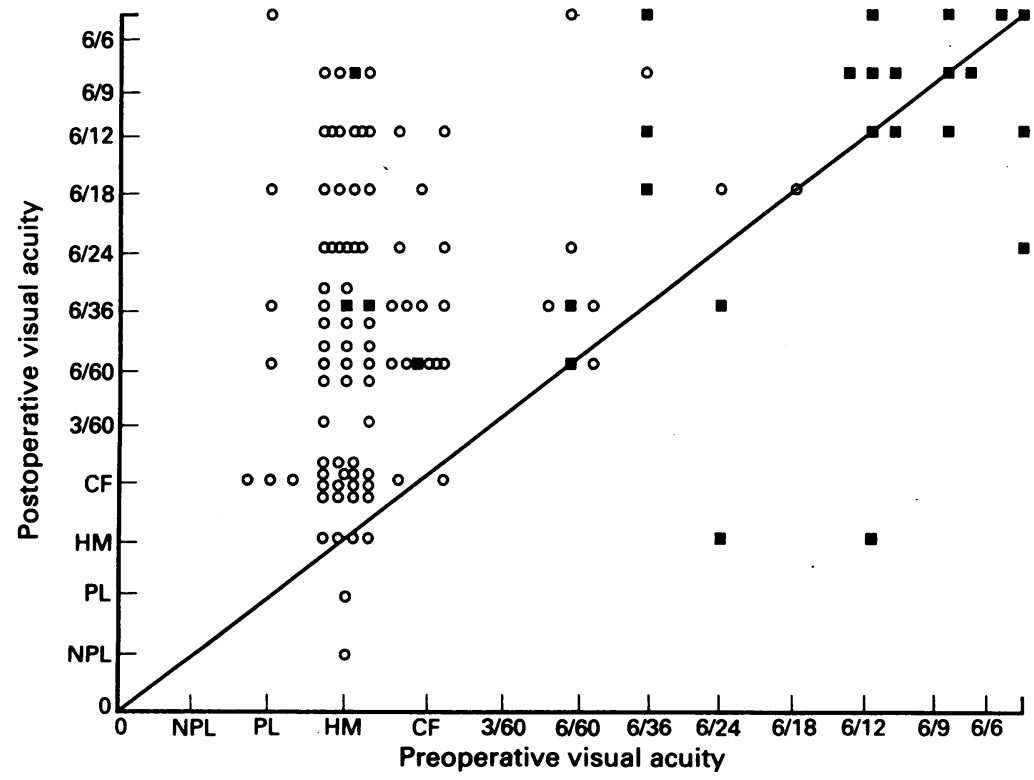

Figure 1 Scattergram of preoperative versus final postoperative visual acuity for all 114 eyes in this study. In 84 eyes the retina was reattached following one operation. The 30 eyes that failed after primary vitrectomy are included. These patients underwent one or more additional procedures. The visual acuity is that measured 6 months after primary vitrectomy or the final intervention in those cases requiring more than one procedure. Open circles represent 'macula off' and solid squares represent 'macula on' detachments. The solid diagnonal line represents the position at which preoperative and postoperative visual acuities are equal and therefore those datapoints above the line represent eyes in which there has been an improvement. was improved in 92 eyes (81\%), unchanged in $14(12 \%)$, and worse in eight $(7 \%)$. We conclude that pars plana vitrectomy is an effective method for treatment of selected cases of rhegmatogenous retinal detachment not complicated by proliferative vitreoretinopathy.

(Brf Ophthalmol 1993; 77: 199-203)

Pars plana vitrectomy (PPV) has become accepted as the treatment of choice for certain complex retinal detachments. The commonest indications are difficult breaks (for example, giant or macula) ${ }^{12}$ or the presence of advanced proliferative vitreoretinopathy (PVR)..$^{3-6}$ In simpler rhegmatogenous retinal detachment (RRD) external buckling procedures are preferred generally. However, the accurate placement of scleral buckles is rendered impossible when breaks can not be identified or difficult when there is an unusually complex arrangement of breaks. Pars plana vitrectomy may be used in these situations but to date its role has not been defined well. The object of this study therefore was to report the results of a series of such patients.

Patients and methods

A retrospective analysis of a consecutive series of 114 eyes (112 patients), previously unreported, undergoing PPV for RRD at St Thomas's Hospital, London (93 eyes) and St Paul's Eye Hospital, Liverpool (21 eyes) was carried out.

CASE SELECTION AND PATIENT DETAILS

A total of 1045 vitrectomies was performed during the study period (1987-91). Only cases with relatively uncomplicated RRD were studied. Those associated with giant or macular breaks, vasoproliferative retinopathy, or a substantial degree of PVR, as defined by the Retina Society Terminology Committee, ${ }^{7}$ were excluded. Cases in which membrane formation was severe enough to warrant direct surgical relief of retinal traction - for example, by membrane peeling, were excluded also.

During admission, patient information was gathered on proforma sheets and entered into the vitreoretinal database (D-base 3 plus; Ashton Tate). In each case the retina was examined by 
Table 1 Reasons for poor retinal view - 62 eyes

\begin{tabular}{|c|c|c|c|}
\hline \multirow[t]{2}{*}{ Cause } & \multicolumn{3}{|c|}{ No of patients } \\
\hline & Total & $\begin{array}{l}\text { No breaks found } \\
\text { preoperatively } \\
\text { (Total }=18)\end{array}$ & $\begin{array}{l}\text { Breaks found } \\
\text { peroperatively } \\
\text { (Total=16) }\end{array}$ \\
\hline \multicolumn{4}{|l|}{ Vitreous opacity: } \\
\hline $\begin{array}{l}\text { Haemorrhage or } \\
\text { turbidity }\end{array}$ & 20 & 6 & 6 \\
\hline \multicolumn{4}{|l|}{ Lens/iris diaphragm: } \\
\hline \multicolumn{4}{|l|}{ IOL/capsule } \\
\hline Small pupil & 14 & 3 & 3 \\
\hline Cataract & 5 & 1 & 1 \\
\hline \multicolumn{4}{|l|}{ Other: } \\
\hline Cornea & 2 & 1 & 1 \\
\hline \multicolumn{4}{|l|}{ Choroidal } \\
\hline Unspecified & 1 & 1 & - \\
\hline
\end{tabular}

indirect ophthalmoscopy with scleral depression and by three-mirror gonioscopy. Colour coded retinal charts were made wherever possible. One hundred and fourteen eyes (112 patients) satisfying the entry criteria were identified from the data base. The follow up period varied from 1 to 4 years (mean 19 months). Age range was 14 81 years (mean 52.6 years). There were 65 males and 49 females. Thirty three eyes had total retinal detachment. In a further 26 , three quadrants were detached and in 55, two quadrants or less. The macula was detached in 88 eyes. Of the 26 eyes with attached maculas the preoperative visual acuity was between hand movements and $6 / 24$ in 11 and $6 / 12$ or better in 15 (Fig 1). The assessment of breaks was based on pre- and peroperative findings. Breaks were multiple in 62 eyes and single in 46. In 26 eyes no breaks were found preoperatively. Early changes of PVR (Grade A-C ${ }^{7}$ ) were detected in 31 eyes.

INDICATIONS FOR VITRECTOMY

Indications for PPV were:

(1) A poor view of the retina (62 eyes, reasons given in Table 1 ).

(2) A difficult arrangement of breaks (44 eyes):

(a) Multiple breaks in more than one quadrant and at different anteroposterior locations (16 eyes).

(b) Breaks posterior to the equator (10 eyes).

(c) Large breaks (18 eyes) - extending more than one clock hour.

(3) The view of a total RRD was good but the break position was uncertain (eight eyes). Therefore, by combining groups 1 and 3 above, a total

Table 2 Preoperative features related to results

\begin{tabular}{lcccc}
\hline Feature & No of cases & $\begin{array}{l}\text { Success with one } \\
\text { operation }\end{array}$ & Final success & Fail \\
\hline Poor view & 62 & $44(71 \%)$ & $58(94 \%)$ & 4 \\
Awkward breaks & 44 & $34(77 \%)$ & $40(91 \%)$ & 4 \\
Uncertain breaks & 8 & $6(75 \%)$ & $7(88 \%)$ & 1 \\
Early PVR & 30 & $21(70 \%)$ & $29(96 \%)$ & 1 \\
No PVR & 84 & $58(69 \%)$ & $77(92 \%)$ & 7 \\
Aphakia & 20 & $15(75 \%)$ & $19(95 \%)$ & 1 \\
$\quad$ (a) Intracapsular & 22 & $17(75 \%)$ & $20(90 \%)$ & 2 \\
(b) Extracapsular & 5 & $4(80 \%)$ & $-(80 \%)$ & 1 \\
AC implants & 13 & $10(77 \%)$ & $2(92 \%)$ & 1 \\
PC implants & 83 & $63(76 \%)$ & $77(93 \%)$ & 6 \\
All breaks buckled & 31 & $21(68 \%)$ & $28(90 \%)$ & 3 \\
Partial or non-buckle (total) & 8 & $6(75 \%)$ & $1(88 \%)$ & 1 \\
$\quad$ (a) partial & 23 & $15(65 \%)$ & $6(91 \%)$ & 2 \\
(b) no buckles & 45 & $32(71 \%)$ & $9(91 \%)$ & 4 \\
Previous conventional RD surgery & & & & \\
\hline
\end{tabular}

of 70 procedures were performed in order to detect breaks. However, in only 26 cases were no breaks detected preoperatively (Table 1 ). This discrepancy arises since in the poor view group $(n=62)$, while one or more breaks were found preoperatively in the majority $(n=44)$, the view was considered to be too poor to place any confidence in whether all breaks had been found and, because of the poor view, it was judged that a conventional procedure would be technically very difficult. Further classification of preoperative features and results achieved is given in Table 2 .

\section{OPERATION DETAILS}

All eyes underwent pars plana vitrectomy using a standard triple port 20 gauge microsurgical technique. As complete a vitrectomy as possible was performed and any obstructing anterior segment opacity removed. Lensectomy was carried out in one case. Indirect ophthalmoscopy with scleral depression was used to search for breaks peroperatively and as the series progressed was aided by deep indentation, microscopy ${ }^{8}$ and the prismatic effect from contact lens tilt. In the majority subretinal fluid (SRF) was drained through retinal breaks during air injection into the vitreous. Retinotomy was performed in 13 eyes where drainage via an anterior break could not be achieved and where the volume of SRF was considered to be too great to allow an adequate gas fill. In all of these cases endolaser was used to seal the retinotomy after gas exchange.

Scleral buckles were used in the majority of cases and in all with early PVR. In 40 eyes, $2 \mathrm{~mm}$ encircling bands were used to aid retention of large silicone rubber explants. In 35 eyes local buckles were used (either silastic sponge or silicone rubber). In 31 all retinal breaks were not buckled (Table 2). Of these, 23 had breaks in superior retina (between 10 and 2 o'clock) which were not buckled since vitreous traction had been relieved sufficiently peroperatively for gas tamponade to keep the break closed in the postoperative period until permanent adhesion had been achieved by cryotherapy or laser reaction. ${ }^{9}$ In the remaining eight cases only inferior breaks were buckled. All breaks were buckled in those patients who had undergone previous conventional retinal detachment surgery (45 eyes).

Gas tamponade of retinal breaks was achieved with either a $30 \%$ ( 89 eyes) or a $20 \%$ (23 eyes) SF6/air mixture. A $12 \%$ propane mixture was used in two- eyes. Cryotherapy was used to produce an intraretinal adhesion in 112 eyes and endolaser photocoagulation in two (excepting the 13 eyes which received endolaser around a retinotomy). Application of cryotherapy was

Table 3 Reasons for failure of the first operation

\begin{tabular}{ll}
\hline Reason & Number \\
\hline Undetected breaks & 18 \\
Iatrogenic breaks (entry site) & 1 \\
Choroidal haemorrhage & 2 \\
Rapid increase in PVR & 3 \\
Uncertain - ? undetected break & 4 \\
Detachment from breaks in previously attached retina & 2
\end{tabular}


preferred to endolaser primarily because of cost although, in addition, it is simple to apply, particularly to peripheral breaks or extensive 'suspicious' areas. Patients were instructed to posture postoperatively to encourage tamponade of retinal breaks.

\section{Results}

\section{REATTACHMENT}

The retina was reattached in 84 eyes with one operation (74\%) and 14 eyes after further surgery $(92 \%)$. Silicone oil was used in six of these reoperations and was still in situ 6 months after surgery. In nine eyes $(8 \%)$ the retina remained detached. The results are related to preoperative features in Table 2.

\section{VISUAL ACUITY}

Best corrected visual acuity was improved in 92 eyes, unchanged in 14 and worse in eight (Fig 1). Almost all cases in which the macula was detached $(\mathrm{n}=88)$ showed improvement in visual acuity $(80 / 88,91 \%)$ and $22(25 \%)$ achieved $6 / 18$ or better (Fig 1). When considering those cases with detached maculas with preoperative VA between perception of light and counting fingers $(\mathrm{n}=80), 72(90 \%)$ improved and $18(22 \cdot 5 \%)$ achieved $6 / 18$ or better 6 months following the final surgical intervention (Fig 1).

\section{PEROPERATIVE BREAK DETECTION}

In 26 eyes no breaks were detected preoperatively. These comprised 18 eyes from the "poor view' group and the eight eyes in which breaks were not found in spite of a good view (group 3 above). With careful internal search with the microscope and deep scleral indentation, breaks were found peroperatively in 16 of the 18 'poor view' eyes and small breaks were located in four of the eight cases in which the view had been good preoperatively.

\section{SURGICAL COMPLICATIONS}

Small iatrogenic breaks occurred in four eyes. Gas went under the retina in two eyes after incarceration of vitreous in a sclerotomy site produced traction on breaks and immobility of adjacent retina (allowing passage of gas through the breaks). Choroidal haemorrhage occurred in four eyes as a result of peroperative hypotony and serous choroidal detachment occurred in three. In two of these placement of sutures had damaged vortex veins. Anterior chamber haemorrhage occurred in one eye with an AC implant and lens touch occurred in two.

\section{FAILURE AFTER THE FIRST PROCEDURE}

Undetected breaks were found to be the cause of redetachment in at least 18 of the 30 eyes that failed after the first procedure (Table 3 ). In one case an entry site break, not seen at the time of vitrectomy, was the cause of redetachment. In three cases redetachment appeared to be due to progressive PVR despite adequate break closure.
In none of the cases where breaks had been deliberately left unbuckled did failure occur because of reopening of such a break. Choroidal haemorrhage led to failure in two cases and in a further four the cause could not be definitely established although failure to close breaks was suspected. Fifteen failures occurred within 4 weeks, 10 between 4 and 8 weeks, and five between 8 weeks and 6 months. To date there have been no failures beyond 6 months (follow up 1 to 4 years; mean 19 months).

\section{REOPERATION}

Of the 30 eyes in which the retina redetached after the first procedure, 25 underwent further surgery. Propane injection alone was successful in two and internal drainage, gas injection, and buckling were successful in 13. In six cases silicone oil tamponade was used at the second vitrectomy due to advanced PVR. In four eyes a second reoperation (third procedure) was performed in which membrane peeling and injection of silicone oil were required.

\section{POSTOPERATIVE INCIDENCE OF PVR}

In 10 cases the development of marked PVR complicated redetachment and silicone oil injection and membrane dissection were considered necessary. Six retinas were reattached but four remained detached of which three had suffered serious preoperative complications during the first operation (choroidal haemorrhage in one and gas under the retina in two).

\section{Discussion}

The role of pars plana vitrectomy (PPV) in the management of complex retinal detachment is well established but its role in simpler cases of rhegmatogenous detachment (RRD) has, to date, been defined poorly. Severe cases of proliferative vitreoretinopathy (PVR) often demand PPV and we therefore excluded those eyes in which direct relief of retinal traction by for example, peeling of preretinal membrane, was the primary aim of the vitrectomy. In this series the indications for vitrectomy in eyes with RRD with minimal or no PVR fell into two main groups: firstly, those eyes in which the view of the retina was grossly impaired (62 cases) and vitrectomy was required to clear the media for accurate identification of retinal breaks, and, secondly, those with large breaks or a more complicated arrangement of breaks ( 44 cases). In this second group vitrectomy relieves vitreoretinal traction enabling break closure by internal tamponade and intraretinal adhesion. It offers a simpler surgical solution without the complications and difficulties of placement of large external scleral buckles. In a smaller third group (eight cases) in which the position of the breaks in a total detachment was uncertain, in spite of a good view, the PPV option with careful internal search was preferred to that of presumptive external buckling. In four of these cases small breaks became apparent at operation.

When the site of the retinal break is obscured by media opacities the choice of PPV appears 
logical. Accurate identification with subsequent intraretinal adhesion with or without buckling would seem a better option than presumptive buckling which is probably only reasonable when the site of an unseen break in partially detached retina can be inferred. ${ }^{10}$ The most frequent cause of poor view in this series was previous cataract surgery (Table 1). In 19 cases an extracapsular approach without complete clearance of peripheral cortex or subsequent thickening of the posterior capsule combined with abnormal reflexes from an intraocular lens led to a poor view. Of these selected 19 pseudophakic cases no breaks were found preoperatively in six (32\%) (Table 1). This compares with 'no break detected' rate of $5 \%$ in a large series of pseudophakic retinal detachments reported by Cousins et $a l .{ }^{11}$ In a further 14 cases the intracapsular approach resulted in a small or distorted pupil. The ease with which capsular remnants can be removed or the pupil enlarged at the time of PPV made this approach particularly suitable for these cases. ${ }^{12}$ The use of PPV in the aphakic eye has the additional advantage that early cataract development owing to inadvertent lens touch or the principal late complication of nuclear sclerosis, which has been shown to occur in up to $50 \%$ of cases, ${ }^{13}$ can not occur. When vitreous haemorrhage reduces retinal visibility significantly removal is also desirable as blood factors enhance PVR formation. ${ }^{14}$ is Newer techniques for detecting retinal breaks were used increasingly throughout the series. ${ }^{8}$ In 18 of the 62 cases in which PPV was performed because of poor view no break was seen preoperatively. However, in 16 of these (89\%) a break was found at operation (Table 1). The capacity to find breaks by careful internal search was improved substantially compared with an earlier series. ${ }^{16}$ These figures confirm the findings of a previous study in which additional breaks were detected at operation, with indentation microsurgery, in 74 of the $78(95 \%)$ selected cases in which either no breaks were detected preoperatively or in which the break detected was not felt to be solely responsible for the detachment. ${ }^{8}$ However, although we detected one break or more in all of the remaining 44 'poor view' cases, in at least 18 of the $\mathbf{3 0}$ cases that failed after one operation an additional break, missed at the time of surgery, was the cause. Improved surgical technique with more conscientious peroperative break searching might have prevented some of these failures but residual peripheral opacities in the media, particularly in the presence of cataract or a lens implant, will probably continue to cause difficulty. When the view of the retina was poor (62 cases) there was a $71 \%$ success rate with one operation and a final success rate of $94 \%$ (Table 2).

Pars plana vitrectomy with internal tamponade, and therefore less dependence on scleral buckling, has led also to a re-evaluation of the role of vitrectomy in management of large breaks or a complex arrangement of breaks. In these cases conventional surgery such as the drain, air injection, cryotherapy, and explant sequence involves extensive scleral buckling with drainage of subretinal fluid and injections into the vitreous cavity. ${ }^{17-19}$ These operations are not only technically difficult to perform when the arrangement of buckles is complex, but, in addition to complications associated with external SRF drainage and gas injection, they also carry an increased risk of postoperative pain, anterior segment ischaemia, oculomotor imbalance, and altered refractive error. ${ }^{20-23}$ In this series scleral buckles were used in all cases of detachment complicated by PVR as it was felt that the proliferative process might progress and reopen unbuckled breaks. Buckles were used in the 45 eyes that had failed after conventional detachment surgery because of the greater risk of PVR development in these cases. In unoperated eyes without PVR breaks were not buckled if it was judged that relief of vitreous traction combined with internal tamponade would be adequate to maintain break closure while an intraretinal adhesion formed. Breaks between 10 and 2 o'clock are particularly suitable for such tamponade but we elected to buckle any breaks detected below one clock hour above the horizontal meridian as it was felt that tamponade would be unreliable below this level. Of the 69 cases that had not undergone previous detachment surgery 23 were treated without buckles at all and in a further eight cases only some of the retinal breaks present (those in inferior retina) were buckled (partial buckle, see Table 2). Of the 31 cases in which 'not all breaks' were buckled $21(68 \%)$ succeeded with one procedure and $28(90 \%)$ were ultimately successful (Table 2). These figures are very similar to the overall percentages for the series. Of the 44 cases in which PPV was performed primarily because of awkward breaks 34 (77\%) were reattached with one operation and six with further surgery. The final success rate was $91 \%$ in this group (Table 2).

The main cause of redetachment after the first operation was failure to detect (and close) all of the retinal breaks in detached retina (Table 3). This is also the commonest cause of failure after conventional detachment surgery. ${ }^{24} \mathrm{~A}$ careful search of flat retina should also be made as it may contain breaks. Unsealed breaks in flat retina in a vitrectomised eye are unforgiving and two cases in this series redetached as a result of an undetected break in previously flat retina (Table 3). Of the 31 eyes in which either none or only some of the breaks were buckled no failures were judged to have been caused by reopening of an unbuckled break. Of the complications encountered at surgery, iatrogenic breaks were recognised in four eyes, were closed and did not contribute to failure. Choroidal haemorrhage however remains a significant complication and two of the four cases in which it occurred subsequently failed as did the two cases where gas had entered the subretinal space. Improving surgical techniques will no doubt lower the incidence of these complications.

We were uncertain of the effect of vitrectomy on the progression of PVR. Of the 30 patients with early PVR $21(70 \%)$ were reattached with one operation compared with a similar number in which there was no obvious PVR ( 58 out of 80 ; $69 \%)$. There were 10 cases $(8 \%)$ in which redetachment was complicated by progression to severe PVR and membrane dissection with 
silicone oil injection was required. In three of these a major complication had occurred during the first PPV procedure but in a further three cases PVR progressed rapidly following an uncomplicated PPV and was considered to be the primary cause of failure. The number of patients in the present study is too small to judge whether failure following PPV for these selected cases is more likely to promote PVR than failure of conventional retinal detachment surgery in a similar group.

This series indicates that PPV is a good surgical option for the type of selected cases described. When the position of breaks is obscured it offers an opportunity for peroperative break detection and closure. When breaks are complex the controlled environment of PPV is an easier surgical option than complex conventional procedures. Although choroidal haemorrhage has rarely occurred during PPV, external drainage complications are avoided and reduced buckling or judicious avoidance of buckles results in fewer postoperative complications. As in all types of retinal detachment surgery failure to identify and seal all breaks remains an important cause of failure

1 Billington BM, Leaver PK. Vitrectomy and fluid/silicone oil exchange for giant retinal tears. Results at 18 months. Graefes Arch Clin Exp Ophthalmol 1986; 224: 7-10.

2 Gonvers M, Machemer R. A new approach to treating retinal detachment with macular holes. Am f Ophthalmol 1982; 94: 468-72.

3 Machemer R. Massive pre-retinal proliferation - a logical approach to therapy. Trans Am Ophthalmol Soc 1977; 35: 556-86.

4 Lean JS, Leaver PK, Cooling RJ, McLeod D. Management of complex retinal detachments by vitrectomy and fluid/silicone oil exchange. Trans Ophthalmol Soc UK 1982; 102: 203-5.

5 Sternberg P, Machemer R. Results of conventional vitreous surgery for proliferative vitreoretinopathy. Am $\mathcal{F}$ Ophthalmol 1985; 100: 141-6.

6 Billington BM, Chignell AH. Treatment of rhegmatogenous retinal detachment uncomplicated by massive peri-retinal proliferation by pars plana vitrectomy. Trans Ophthalmol Soc UK 1985; 104: 120-2

7 Machemer R, Aaberg TM, Freeman HM, Irvine AR, Lean JS, Michels RM. An updated classification of retinal detachment with proliferative vitreoretinopathy. Am f Ophthalmol 1991; 112: 159-65.

8 Rosen PH, Wong HC, McLeod D. Indentation microsurgery: internal searching for retinal breaks. Eye 1989; 3: 277-81.

9 Escoffery RF, Olk RJ, Grand MG, Boniuk I. Vitrectomy without scleral buckling for primary rhegmatogenous retinal without scleral buckling for primary rhegmatogen

10 Lincoff H, Geiser R. Finding the retinal hole. Arch Ophthalmol 1971; 85: 565-9.

11 Cousins S, Boniuk I, Okun E, Johnston GP, Arribas NP, Escoffery RF, et al. Pseudophakic retinal detachments in the presence of various IOL types. Ophthalmology 1986; 93: 1198-208.

12 McHugh D, Wong D, Chignell AH, Leaver PK, Cooling RJ. Pseudophakic retinal detachment. Graefes Arch Clin Exp Ophthalmol 1991; 229: 521-5.

13 de Bustros S, Thompson JT, Michels RG, Enger C, Rice TA, Glaser BM. Nuclear sclerosis after vitrectomy for idiopathic epiretinal membranes. Am f Ophthalmol 1988; 105: 160-4.

14 Campochiaro PA, Jerdon JA, Glaser BM. Serum contains chemoattractants for human retinal pigment epithelial cells. Arch Ophthalmol 1984; 102: 1830-33.

15 Campochiaro PA, Glaser BM. Platelet derived growth factor is chemoattractant for human retinal pigment epithelial cells. Arch Ophthalmol 1985; 103: 576-9.

16 Wong D, Billington BM, Chignell AH. Pars plana vitrectomy for retinal detachment with unseen retinal holes. Graefes Arch Clin Exp Ophthalmol 1987; 225: 269-71.

17 Stanford MR, Chignell AH. Surgical treatment of superior bullous rhegmatogenous detachments. Br $\mathcal{f}$ Ophthalmol 1985; 69: 729-33.

18 Gilbert C, McLeod D. D-ACE surgical sequence for selected bullous retinal detachment. $\mathrm{Br} \mathcal{F}$ Ophthalmol 1985; 69: 7337 .

19 Wong D, Chignell AH, Inglesby D, Little B, Franks WA. The treatment of superior bullous retinal detachment. Graefes treatment of superior bullous retinal detach

20 Goel R, Crewdson J, Chignell AH. Astigmatism following retinal detachment surgery. Br $\mathcal{F}$ Ophthalmol 1983; 67: 3279.

21 Rubin ML. The induction of refractive errors by retinal detachment surgery. Trans Am Ophthalmol Soc 1975; 3: 45290.

22 Fison PN, Chignell AH. Diplopia after retinal detachment surgery. Br $\mathcal{F}$ Ophthalmol 1987; 71: 521-5.

23 Mets MB, Wendell ME, Wendell CO, Gieser RG. Ocular deviation after retinal detachment surgery. Am $\mathcal{F}$ Ophthalmol 1985; 99: 667-72.

24 Chignell AH, Fison LG, Davies EWG, Hartley RE, Gundry MF. Failure in retinal detachment surgery. Brf Ophthalmol 1973; 57: 525-30. 